Ger J Exerc Sport Res 2022 · 52:39-49 https://doi.org/10.1007/s12662-021-00756-0 Received: 13 October 2020

Accepted: 31 August 2021

Published online: 7 October 2021

(c) The Author(s) 2021

\section{Introduction}

The legal and human rights situation of lesbian, gay, bisexual, transgender, queer, and sexually/gender diverse (LGBTQ+) people in Europe has improved over the past decades (European Commission, 2015). This is also documented in the most recent Rainbow Index of the International Lesbian and Gay Association (ILGA, 2020), which ranked Germany 16th among 49 European countries regarding the implementation of legal and human rights. At the same time, international research on LGBTQ+ individuals in sports has increased over the last decade, particularly in Anglophone countries. There is growing empirical evidence that LGBTQ+ people regularly experience discrimination and exclusion in sports (Denison, Bevan, \& Jeanes, 2020; Kavoura \& Kokkonen, 2020). However, there is a dearth of research on the situation of LGBTQ+ athletes in Germany (Krell \& Oldemeier, 2018; Schweer, 2018).

This lack of empirical research corresponds to a lack of awareness of potential discrimination against LGBTQ+ people in sports in Germany. Although the German Olympic Sports Confederation and its member organizations explicitly commit to the strategy of sport for all and have integrated equality of opportunities and/or antidiscrimination in its statutes (Deutscher Olympischer Sportbund, 2019), only a minority of the sports organizations mention LGBTQ+, sexual orientation, and/or gender identity as one of their antidiscrimination priorities (Csonka, 2019; Vedder \& Lammert, 2015).

Against this backdrop, the purpose of this paper is twofold. Based on

Ilse Hartmann-Tews (D) - Tobias Menzel · Birgit Braumüller

Institute of Sociology and Gender Studies, German Sport University Cologne, Cologne, Germany

\title{
Experiences of LGBTQ+ individuals in sports in Germany
}

a quantitative survey of 858 self-identifying LGBTQ+ individuals, this study investigates the experiences of LGBTQ+ athletes in Germany and the impact of the sports context on homo- and transnegative incidents. In addition, it provides practical knowledge for sports policymakers' efforts to make sports more inclusive.

\section{Literature review and theoretical background}

The acronyms LGBTQ+, GSM (gender and sexual minorities), and GSD (gender and sexually diverse individuals) are umbrella terms used in international studies to specify the group that is the focus of the research. Although the term LGBTQ+ is accepted in activism and the political arena, it is an all-encompassing, homogenizing term that runs the risk of masking important distinctions between individuals. One focus of the term is on sexual orientation (lesbian, gay, bisexual, and sexually diverse persons), denoting people who are emotionally and sexually not (only) attracted to the opposite sex and who are not heterosexual/straight. The other focus is on gender identity, denoting people whose sex assigned at birth does not match their gender identity (transgender) and individuals who question the binary gender order and do not want to position themselves within this binary of male/female (queer, +). Intersex, referring to a "condition of possessing the sexual characteristics of both sexes" (American Psychology Association, 2021), is often implicitly or explicitly included in the acronyms and umbrella terms. Despite its proximity to issues concerning gender identity and sexual orientation, it is instead a clinical phenomenon in which biological conditions lead to an atypical development of sex characteristics.

There is a scarcity of research on LGBTQ+ issues in sports that takes into account the diversity of people within the umbrella term LGBTQ+ and considers sexual orientation and/or gender identity and its intersections. Most of the quantitative and qualitative studies in sports have focused on LGB people only (e.g., Anderson, Magrath, \& Bullingham, 2016; Denison \& Kitchen, 2015). Only recently has there been a growing number of qualitative studies focused on the specific situations and challenges of transgender people in sports (e.g., Devís-Devís, Pereira-García, Fuentes-Miguel, López-Cañada, \& Pérez-Samaniego, 2018; Jones, Arcelus, Bouman, \& Haycra, 2017; Semerjian, 2019).

The most comprehensive data regarding LGBTQ+ people in sports come from two international studies. Denison \& Kitchen (2015) documented the sports experiences of about 7000 LGB athletes in six countries (USA, Canada, UK, Ireland, NZ, and Australia), while HartmannTews, Menzel, \&Braumüller (2020) analyzed the situations and experiences of about 5500 LGBTQ+ people from all over Europe. Apart from these large international quantitative studies, smallscale quantitative and qualitative studies in a wide range of sports settings have provided evidence that LGBTQ+ athletes regularly experience discrimination and exclusion in the form of homo- 
and transnegativity (e.g., Denison, Bevan, \& Jeanes2020). ${ }^{1}$

The reported percentages of respondents who have witnessed or experienced discrimination, harassment, and exclusion in a sporting environment vary between $16 \%$ and $80 \%$ (Demers, 2017; Denison \& Kitchen, 2015; HartmannTews et al., 2020; Smith, Cuthbertson, \& Gale, 2012). These variations could be due to different research designs, the wording of the questions, and the reference time (period) of the experiences. The predominant nature of both witnessed and experienced homoand transnegativity is verbal, as almost all LGBTQ+ people in these studies reported experiencing verbal jokes, disparagement, slurs, insults, and offensive remarks. Physical assaults have been reported as well, but on a far lower scale, with respondents who had personally experienced homo-/transnegative violence ranging between 3\% (Australian Capital Territory [ACT] Government, 2014; Symons, Sbaraglia, Hillier, \& Mitchell, 2010) and 19\% (Denison \& Kitchen, 2015). These quantitative findings are consistent with a growing number of qualitative studies based on interviews and group discussions (Greenspan, Griffith, \& Watson, 2019; Hargie, Mitchell, \& Sommerville, 2017).

The experience of homo- and transnegativity in society and sports is frequently used to explain mechanisms of (self-)exclusion, such as the lower participation rates of LGBTQ+ individuals in sports (Cleland, 2018; Greenspan et al., 2019; Scandurra, Braucci, Bochicchio, Valerio, \& Amoedo, 2019). Several studies have indicated that gender and sexual minorities feel excluded from physical activities and sports due to their sexual orientation or gender identity. These findings have consistently shown a higher rate of gay men compared to lesbian women who

\footnotetext{
1 The authors prefer the terms homonegativity and transnegativityinstead of the common terms homophobia and transphobia. Phobia implies an irrational fear, which is often linked to avoiding a specific phobic context. By contrast, the terms homo-/transnegativity more adequately grasp the active enactment of negative attitudes and discriminatory behaviours (MacDonald, 2018; Schweer, 2018).
}

feel excluded (Denison \& Kitchen, 2015), whereas the findings concerning the perceptions of transgender individuals have been mixed (ACT Government, 2014; Denison \& Kitchen, 2015; Symons et al., 2010). Moreover, data consistently show that discriminatory experiences deter LGBTQ+ youth from playing sports (Greenspan et al., 2019). The evidence is stronger for males than for females and transgender people. However, some empirical studies have identified equal or higher participation rates of LGBTQ+ individuals compared to their heterosexual and cisgender counterparts (Doull, Watson, Smith, Homma, \& Saewyc, 2018; Elling \& Janssens, 2009; Yoon \& So, 2013). With regard to sports participation in Germany, Krell \& Oldemeier (2018) identified a lower sports participation rate for LGBTQ+ persons aged 14-27 years compared to non-LGBTQ+ individuals, with transgender females having the lowest participation rate.

To understand homo- and transnegative attitudes and actions towards LGBTQ+ athletes and the respective experiences and feelings of the targeted individuals, Cunningham's (2019) multilevel model and Meyer's (2003) model of minority stress offer useful analytical frameworks. Both authors utilized sociological and social psychological theories regarding inclusion/exclusion and conflicts that arise when minority groups are not adequately acknowledged and are marginalized in dominant cultures.

Cunningham (2019) identified three levels that reflect attitudes towards LGBTQ+ people and have an impact on the experiences of these individuals in general and in sports in particular: the macro level (e.g., laws and cultural norms), the meso level (e.g., organizational culture), and the micro level (e.g., individual identity and interaction).

With regard to macro-level factors, general social structures (e.g., norms, values, and practices) serve to privilege the norm-conforming majority (i.e., heterosexuals and cisgender individuals) while marginalizing the non-conforming minority (i.e., sexual minorities and transgender individuals). These norms, values, and practices are built upon the common understanding that there is a natural, biological, and hierarchical binary gender order (boy/girl, man/ woman, and male/female) and natural, biologically determined same-sex attraction. In Krane's (2019) book Sex, Gender, and Sexuality in Sport, the author denoted the respective macro-level structures of the heteronormative gender order, indicating binary and heterosexuality as the normative frame of society. Although there is growing awareness of LGBTQ+ people and acceptance of their human rights, as reflected in the ILGA (2020) Rainbow Score, there is still a structural stigma regarding LGBTQ+ persons (Herek, 2009) that gives way to practices of othering, discrimination, and exclusion.

At the meso level, these norms and values are reproduced and strengthened by organizational agents who operate within this social context. As the generalized mindset and core activities of sports are based on the "communication of body-centered performances" (Hartmann-Tews, 1996, p. 34), the social structures of sports are laid out to reinforce the traditional binary and heteronormative gender order of society. One of the characteristics of the sportsspecific social structure is rigid sex segregation in competitive sports. Moreover, there are policies regarding the inclusion and exclusion of transgender and intersex persons (e.g., testosterone benchmarking for female transgender and intersex athletes) that are based on the binary order. Although these rules were established to guarantee a level playing field, they represent and enforce the hierarchical binary gender order and are highly debated (Gleaves \& Lehrbach, 2016; Semerjian, 2019). Moreover, historical research has documented the male-dominated culture of sports, which privileges males, masculinity, and heterosexuality (Connell \& Messerschmidt, 2005). These patterns of shared values and social structures are multiplied through formal and informal organizations (sports federations, clubs, leagues, and teams) and in sports contexts (e.g., team/individual sports, competitive/leisure sports, and club-based/informal sports) that mold the behaviors of their members. Melton and Cunningham (2012) confirmed the 
relevance of the meso level, documenting that organizational culture regarding the acceptance of diversity affects the wellbeing of minority groups and the coming out of homosexual athletes.

Finally, micro-level factors, which operate at the individual level, are embedded in and influence macro- and meso-level factors. They refer primarily to characteristics of the individual (e.g., LGBTQ+ status, age, and social/cultural background) and interactions between people. LGBTQ+ people are mostly considered a single minority group varying from the standard and are consequently cast as the other. A closer look at the individual level reveals the heterogeneity within this community and the necessity of considering the individual LGBTQ+ status in order to reveal diverse vulnerabilities (Fink, 2008). From another perspective, there is evidence that demographics and (salient) identities play a role with regard to homo-/ transnegative attitudes; in particular, Bush, Anderson, \& Carr (2012) identified how males and athletes who closely identify with competitive sports culture express more sexual prejudice than athletes with a weaker athletic identity.

The different levels, however, should not be considered as operating in isolation. Instead, it should be recognized that the macro, meso, and micro levels are embedded in and influence one another. In addition to this multi-level perspective of social structures influencing the experiences of LGBTQ+ persons, Meyer's (2003) minority stress model identified different types of stressors among LGBTQ + individuals due to their experiences of homo-/transnegativity. Minority stressors exist on a continuum ranging from distal to proximal. Distal stressors are external objective events and conditions (e.g., experiences of prejudice, discrimination, and violence) enacted by individuals at the micro level or social structures at the macro and meso levels of systems and organizations. Proximal stressors are more subjective, referring to internal thoughts and processes, and are related to self-identity (micro level). They pertain to the internalization of societal values (macro level) in general and, in particular, to environ-

Ger J Exerc Sport Res 2022 · 52:39-49 https://doi.org/10.1007/s12662-021-00756-0

(c) The Author(s) 2021

\section{Hartmann-Tews · T. Menzel • B. Braumüller \\ Experiences of LGBTQ+ individuals in sports in Germany}

\section{Abstract}

There is growing international evidence that lesbian, gay, bisexual, transgender, queer, and sexually/gender diverse (LGBTQ+) people regularly experience discrimination in sports. However, there is a lack of empirical research with regard to the sports situation in Germany. Based on a quantitative survey of 858 self-identifying LGBTQ+ individuals, the present research is the first to provide a comprehensive picture of the experiences of $L G B T Q+$ people in sports in Germany. To add distinctive knowledge to the international research, this analysis considers differences within the group of LGBTQ+ people and between various sports settings (i.e., organizational framework, team vs individual sports, and performance level. Two research questions are addressed: (1) What micro- and meso-level factors affect the witnessing of homo-/transnegative language and the prevalence of homo-/ transnegative incidents in respondents' sports activities? (2) What micro- and mesolevel factors affect respondents' feelings of being offended by homo-/transnegative language and what behavioral consequences (i.e., refraining from specific sports and reactions to homo-/transnegative episodes) can be observed among different LGBTQ+ subgroups? The data reveal the impact of the sports context on the perception of homo-/ transnegative language but not on negative experiences. Moreover, there is a higher prevalence of gay compared to lesbian athletes with regard to the perception of homo-/transnegative language in their sports and a higher prevalence of gay athletes and non-cisgender (transgender) athletes with regard to homo-/transnegative experiences in sport compared to lesbian and cisgender athletes. The empirical evidence confirms and deepens international findings. Moreover, the data assist the Sport Ministers Conference's goal of increasing initiatives to tackle the exclusion and discrimination faced by LGBTQ+ people in sports.

\section{Keywords}

Discrimination - Gender identity · Homophobia. Sexual orientation $\cdot$ Transphobia ment-specific attitudes (meso level) and their behavioral consequences. Against this background, there has been growing evidence that LGBTQ+ individuals are characterized by (additional) stress based on their minority status and that they have a higher prevalence of health disorders compared with heterosexuals, with distal and proximal stressors intermingling and mediating the effects (LeBlanc, Frost, \& Wight, 2015; Meyer, 2003).

\section{Research questions}

In this article, two research questions are addressed with regard to the situations and experiences of LGBTQ+ individuals in sports in Germany. First, with regard to distal stressors of homo-/ transnegativity in sports, what microlevel factors (sexual orientation and/or gender identity) and meso-level factors (organizational frame, type of sports, and performance level) affect the witnessing of homo-/transnegative language and the prevalence of homo-/transnegative incidents in respondents' sports activities? Second, with regard to proximal stressors, what micro- and meso-level factors affect respondents' feelings of being offended by homo-/transnegative language and what behavioral consequences (i.e., refraining from specific sports and reactions to homo-/transnegative episodes) can be observed among different LGBTQ + subgroups?

\section{Method}

\section{Sample}

The authors conducted a systematic, web-based sampling approach to target LGBTQ+ individuals who were at least 16 years old and living in Germany. The survey, which was part of an ERASMUS+ project, was provided in German. To tackle the challenges related to sampling hard-to-reach, hidden, and vulnerable populations, the recruitment efforts were maximized by using a com- 
bination of sampling strategies (EllardGray, Jeffrey, Choubak, \& Crann, 2015; Menzel, Braumüller, \& Hartmann-Tews, 2019). The online survey was accessible between March and August 2018. Participants' anonymity and confidentiality were secured, and the EU General Data Protection Regulation was followed. The research design was approved by the ethics committee of the German Sport University Cologne.

\section{Measures of key concepts}

Sexual orientation. The measurement of self-identified sexual orientation was adapted from different studies (e.g., European Union Agency for Fundamental Rights, 2014; Parent \& Bradstreet, 2018; Symons et al., 2010). It was assessed using a categorical measure ("How do you describe yourself?") with the following response options: (1) heterosexual/ straight, (2) gay man, (3) lesbian woman, (4) bisexual, (5) other, (6) not sure, and (7) prefer not to say.

Gender identity. To retrieve data regarding the gender identity of the participants, a two-question gender status measure that encompasses a diversity of identities was adapted from Broussard, Warner, and Pope (2018) and Tate, Ledbetter, and Youssef (2013). First, respondents were asked to report their sex assigned at birth, with the options (1) male and (2) female. Second, they were asked about their current gender identity and presented with four options: (1) female, (2) male, (3) transgender, and (4) I do not identify myself as male, female, or transgender. Cross-analysis of the answers to these two questions resulted in two categories: cisgender persons (a binary gender identity category denoting the correspondence between sex assigned at birth and (current) gender identity) and non-cisgender persons (a term used to describe people whose gender identity does not match the sex that they were assigned at birth). A further differentiation resulted in two cisgender categories (cisgender female and cisgender male) and four non-cisgender categories ( $f e$ male transgender, male transgender, non- binary transgender, and non-identifying people).

Sports participation and context. To assess their current involvement in sports, respondents were asked whether they had participated in sports in the previous 12 months (options: yes or no) and, if so, which of the sports activities that they took part in during the previous 12 months was most important to them. Based on the responses, a categorization of the type of sport was conducted (team sports and individual sports). Performance level was assessed by a single-choice question ("What was the nature of this activity?") with the following response options: (1) recreational, (2) competitive, and (3) high performance. The organizational frame of the sport was assessed by a singlechoice question ("In which setting did this sports activity take place?") with six response options. Within the scope of this paper, respondents who practiced their sports in organized sports clubs were contrasted with other organizational frames: for-profit organizations, other organizations (e.g., company sports or university sports), informal groups, and alone.

Homo-/transnegative language. This language was defined as "the use of expressions like 'that's so gay' and derogatory words and/or jokes about sexual orientation and gender identity issues," regardless of the intentions. Respondents were asked whether they had witnessed the use of homo-/transnegative language in the last 12 months in their main sport, using a five-point scale ( $1=$ never, $5=$ very often). To assess the offence, they were subsequently asked, "Did you feel discriminated against or offended by this language?" (with the same five response options). When percentages are used to describe the proportion of respondents, we generally refer to dichotomized data. In this case, the dichotomized data related to the number of offences experienced $(1=$ no, $2-5=$ yes $)$.

Negative personal experiences. The participants were asked whether or not (options: yes or no) they had had nega- tive personal experiences in their main sport within the previous 12 months related to their sexual orientation and/or gender identity. In addition, they were asked to indicate how often they had personally experienced specific forms of negative events (six categories ranging from verbal insults/slurs to physical violence and one category for other forms). Respondents were provided with a fivepoint scale response option $(1=$ never, $5=$ very often) for each form. The scale was dichotomized $(1=$ no, $2-5=$ yes $)$, and percentages were used to indicate the proportion of respondents who experienced specific types of incidents.

\section{Statistical methods}

The results are presented with regard to the association of the independent variables (sexual orientation, gender identity, and sports contexts) with the dependent variables (witnessing homo-/ transnegative language, having negative experiences, and feeling excluded from sports). Frequencies and percentages are presented to provide a descriptive overview. Chi-square $\left(\mathrm{X}^{2}\right)$ independence tests with Cramer's V effect size were used to test distributional changes in the dichotomized dependent variable within the categories of the independent variables. Two multiple linear regression models were calculated to predict the frequencies of (a) witnessing homo-/ transnegative language and (b) feeling offended by the same language. A binary logistic regression model was calculated to predict the relationships between respondents' sexual orientation, gender identity, sports contexts, and likelihood of a personally experienced homo-/ transnegative incident in their sport. SPSS 26 (IBM, Armonk, NY, USA) was utilized, and statistical significance was set at the 0.05 level.

\section{Results}

\section{Composition of the sample}

The final sample contained 858 valid cases. Participants' ages ranged from 16 to 74 years, with a mean value of 33.1 years (standard deviation $[S D]=11.7$ ). The 
Table 1 Composition of the sample with regard to sex and gender identity

\begin{tabular}{|l|l|}
$\boldsymbol{n}$ & $\%$ \\
\hline 642 & 74.8 \\
\hline 383 & 44.6 \\
\hline 259 & 30.2 \\
\hline 216 & 25.2 \\
\hline 30 & 3.5 \\
\hline 44 & 5.1 \\
57 & 6.6 \\
85 & 9.9 \\
\hline 858 & 100 \\
\hline
\end{tabular}

level of education was relatively high: $57.8 \%$ of respondents had a college or university degree compared to $28 \%$ of the German population (25-65 years of age; Autorengruppe Bildungsberichterstattung, 2020). - Table 1 shows the composition of the sample with regard to sex and gender identity. The majority of participants $(74.8 \%)$ were cisgender persons, with a higher proportion of females compared to males, while $25.2 \%$ were non-cisgender persons, of whom the majority described themselves as non-identifying $(9.9 \%)$ or non-binary transgender $(6.6 \%)$. With regard to the sexual orientation of respondents in the sample, $34.4 \%$ identified as lesbian women, $28.8 \%$ as gay men, $16.8 \%$ as bisexual, $12.3 \%$ as "other," $4.2 \%$ as "not sure," $2.0 \%$ as heterosexual/straight (all non-cisgender respondents), and $1.5 \%$ as "prefer not to say." In order to build sufficiently large categories, sexual orientation was summarized using four categories: lesbian women $(34.4 \%)$, gay men $(28.8 \%)$, bisexual people $(16.8 \%)$, and all others $(20.0 \%)$. Irrespective of sexual orientation and gender identity, $3.7 \%$ of all respondents additionally indicated having an intersex condition.

\section{Physical activity}

The overwhelming majority of respondents (84.8\%) were physically active and participated in sports at the time of the survey; of these, most (68.1\%) were involved in recreational sports, while around one-quarter $(27.4 \%)$ were in competitive sports, and only a small proportion $(4.5 \%)$ were in high-performance sports. With regard to the organizational frame of the sports activities, $42.1 \%$ practiced their main sport in organized sports clubs, while $57.9 \%$ practiced their main sport in other organizational frames. Only $3.1 \%$ of all respondents had never been physically active (with the exception of physical education in school), while a further $12.0 \%$ had been previously active but had stopped doing sports.

More than one-fifth of all respondents (22.1\%)-whether physically active or not-stated that they had refrained from certain sports due to their sexual orientation and/or gender identity. With regard to gender identity, the data showed significant differences between cisgender and non-cisgender participants. More than half of the non-cisgender respondents $(55.8 \%)$, compared to $10.6 \%$ of cisgender respondents, felt excluded from particular sports or had at one point stopped participating in a particular sport as a result of their gender identity $\left(\chi^{2}(1)=184.0, p<0.001 ; V=0.474\right)$. Male transgender respondents were the most likely to refrain from sports $(73.2 \%)$, whereas female cisgender people were the least likely (7.1\%).

\section{Witnessing and being afflicted by homo-/transnegative language}

Overall, homo- or transnegative language was witnessed by almost half (45.2\%) of athletes in their main sports activity in the 12 months prior to the survey. There were no group differences concerning gender and gender identity, but significant effects were found regarding the sexual orientation of cisgender athletes and the sports contexts.

There was a higher proportion of gay men (50.0\%) and respondents with other sexual orientations (64.5\%) who witnessed homo- and transnegative language compared to lesbian women $(39.2 \%)$ and bisexual respondents $\left(39.2 \% ; \quad \chi^{2}{ }_{(3)}=11.23, \quad p<0.05\right.$, $V=0.141)$. The prevalence of witnessing homo-/transnegative language also significantly varied between the sports contexts (i.e., organizational frame, performance level, and type of sport). Homo-/transnegative language was more frequently witnessed in organized sports clubs $(52.3 \%)$ than in all other organizational frames $\left(39.8 \% ; \chi^{2}(1)=11.22\right.$, $p<0.001, V=0.124)$. Moreover, it was more frequently witnessed in highperformance $(69.2 \%)$ and competitive sports $(60.4 \%)$ compared with leisure sports $\left(45.1 \% ; \quad \chi^{2}(2)=14.52, p<0.001\right.$, $V=0.158)$. It was also more frequently witnessed in team sports (62.6\%) compared with individual sports (39.9\%; $\left.\chi^{2}(1)=27.73, p<0.001, V=0.195\right)$. Handball (78.6\%), football/soccer (66.7\%), and rugby (63.9\%) were most often specified as sports that displayed the use of homo-/ transnegative language.

A multiple linear regression was calculated to predict the frequency of witnessing homo-/transnegative language based on respondents' gender identity and sexual orientation and the sports context variables (organizational frame, performance level, and type of sport; $\mathrm{F}_{(11,564)}=4.89, p<0.001$; corrected $\left.R^{2}=0.069\right)$. Due to nonnormally distributed residuals, bootstrapping (BCa method with $n=10,000$ samples) was used to correct the standard errors of the estimated parameters. Participation in individual sports (compared to team sports) was found to significantly decrease the frequency of witnessing homo-/transnegative language $(\beta=-0.18, p<0.001)$. Participation in competitive $(\beta=0.15, p<0.001)$ and high-performance sports $(\beta=0.14$, $p<0.05$; compared to recreational sports), as well as being a gay man (compared to being a lesbian woman; $\beta=0.17$, $p<0.001$ ), significantly increased this frequency. Controlling for all other variables, the organizational frame was not found to be a significant predictor of frequency of witnessing homo-/ transnegative language (• Table 2).

Of those who witnessed homo-/ transnegative language in their main sport, the vast majority (78.1\%) felt discriminated against or offended by this kind of language. The proportion of respondents and the extent to which these respondents felt offended or discriminated against by the use of homo-/transnegative language varied significantly with respect to both gender identity $\left(\chi^{2}{ }_{(1)}=12.42, p<0.001\right.$, 
Table 2 Multiple linear regression analysis of variables predicting witnessing homo-/ transnegative language $(\mathrm{HTL}) ; n=575)$ and feeling offended by HTL $(n=289$

\begin{tabular}{|c|c|c|c|c|c|c|}
\hline \multirow{2}{*}{ Variable } & \multicolumn{3}{|c|}{ Witnessing HTL } & \multicolumn{3}{|c|}{ Feeling offended by HTL } \\
\hline & B & SE Ba & $\beta$ & B & SE $B^{1}$ & $\beta$ \\
\hline \multicolumn{7}{|c|}{ Organizational frame (Ref. organized sports clubs) } \\
\hline $\begin{array}{l}\text { For-profit organization (e.g., fitness } \\
\text { center) }\end{array}$ & 0.23 & 0.12 & 0.09 & 0.37 & 0.21 & 0.13 \\
\hline $\begin{array}{l}\text { Other organization (e.g., company } \\
\text { sport.) }\end{array}$ & 0.27 & 0.19 & 0.07 & 0.44 & 0.33 & 0.09 \\
\hline $\begin{array}{l}\text { Informal group (non-organized/self- } \\
\text { organized) }\end{array}$ & 0.09 & 0.13 & 0.03 & -0.13 & 0.26 & -0.03 \\
\hline Other & 0.04 & 0.25 & 0.01 & -0.21 & 0.44 & -0.03 \\
\hline \multicolumn{7}{|l|}{ Type of sport (Ref. team sports) } \\
\hline Individual sports & -0.41 & 0.11 & $-0.18^{* * *}$ & 0.26 & 0.16 & 0.10 \\
\hline \multicolumn{7}{|l|}{ Performance level (Ref. recreational) } \\
\hline Competitive & 0.36 & 0.10 & $0.15^{* * *}$ & 0.01 & 0.16 & 0.00 \\
\hline High performance & 0.72 & 0.30 & $0.14^{*}$ & 0.22 & 0.32 & 0.04 \\
\hline \multicolumn{7}{|l|}{ Gender identity (Ref. cisgender) } \\
\hline Non-cisgender & 0.24 & 0.16 & 0.09 & 0.71 & 0.20 & $0.24^{* * *}$ \\
\hline \multicolumn{7}{|l|}{ Sexual orientation (Ref. lesbian) } \\
\hline Gay & 0.38 & 0.11 & $0.17^{* * *}$ & -0.01 & 0.17 & 0.00 \\
\hline Bisexual & -0.01 & 0.12 & 0.00 & -0.30 & 0.19 & -0.09 \\
\hline Other & 0.07 & 0.17 & 0.03 & 0.23 & 0.23 & 0.07 \\
\hline$R^{2}$ & - & - & 0.087 & - & - & 0.136 \\
\hline$R^{2}$ (corr.) & - & - & 0.069 & - & - & 0.102 \\
\hline Model (F) & - & - & $4.89 * * *$ & - & - & $3.99^{* * * *}$ \\
\hline
\end{tabular}

$V=0.194)$ and type of sport $\left(\chi^{2}(1)=4.10\right.$, $p<0.001, V=0.112)$.

Most (92.4\%) non-cisgender respondents who witnessed homo-/transnegative language reported feeling offended by this, compared to $73.6 \%$ of cisgender individuals. With regard to the sports context, the only difference found was that more athletes involved in individual sports $(81.4 \%)$ than in team sports (71.6\%) felt offended by this language. No differences were observed with regard to organizational frame or performance level.

A multiple linear regression was calculated to predict the frequency of feeling offended by the use of homo-/ transnegative language $\left(\mathrm{F}_{(11,278)}=3.99\right.$, $p<0.001 ; \quad$ corrected $\left.\mathrm{R}^{2}=0.102\right)$, again using BCa bootstrapping with 10,000 samples to estimate robust standard errors and significance. A significant effect of gender identity was found $(\beta=0.24$, $p<0.001)$, suggesting that being noncisgender increased the frequency of feeling offended. The type of sport did not significantly predict the frequency of feeling offended $(\beta=0.10, p=0.105)$, nor did any of the other included sports context variables (• Table 2 ).

\section{Negative personal experiences}

Regarding personal experiences, $12.9 \%$ of all athletes reported having had negative personal experiences associated with their sexual orientation and/or gender identity in their main sport in the 12 months prior to the survey. The most striking significant differences were between non-cisgender and cisgender athletes. The proportion of noncisgender athletes with negative personal experiences was four times higher (31.9\%) than for cisgender athletes (7.3\%; $\left.\chi^{2}(1)=69.15, p<0.001, V=0.308\right)$. This effect occurred consistently for all organizational forms, all performance levels, and all types of sports. Within the group of non-cisgender respondents, female transgender (30.0\%), non-binary transgender (33.3\%), and non-identifying individuals $(42.4 \%)$ were particularly affected, in contrast to a lower proportion of male transgender individuals (13.2\%). However, within-group differences were significant only with regard to cisgender athletes: Cisgender males had twice the share of negative experiences compared to their female counterparts $\left(10.7 \% / 5.0 \% ; \quad \chi^{2}{ }_{(1)}=6.44\right.$, $p<0.05, V=0.107)$, and gay men had a significantly higher prevalence (11.4\%) compared to lesbian women (5.2\%), bisexual athletes $(3.1 \%)$, and athletes with other sexual orientations (9.7\%; $\left.\chi^{2}(3)=9.49, p<0.05, V=0.130\right)$. In contrast to these effects of gender identity and sexual orientation on negative experiences, there was no significant correlation between personal negative experiences and sports context (i.e., organizational frame, performance level, and type of sport).

A binary logistic regression was conducted to predict the likelihood of a homo-/transnegative incident based on respondents' gender identity, sexual orientation, and sports context variables (organizational frame, performance level, and type of sport; - Table 3). The overall logistic regression model was significant (with a likelihood ratio test of $\left.\chi^{2}(11)=70.83, p<0.001\right)$. Goodness-of-fit statistics suggested that the model fitted the data well, yielding an insignificant Hosmer-Lemeshow test $\left(\chi^{2}{ }_{(8)}=5.680\right.$, $p=0.683)$ and a pseudo $\mathrm{R}^{2}$ (Nagelkerke) of 0.219 . The model included dummy variables for each categorical predictor. Gender identity was identified as a significant predictor $(\mathrm{B}=2.434, p<0.001)$, with an odds ratio of 11.35 for non-cisgender compared to cisgender respondents (95\% CI: 5.17, 24.95). Sexual orientation was also found to significantly predict the likelihood of a homo-/transnegative incident $\left(\operatorname{Wald}_{(3)}=15.03, p<0.01\right)$. Accordingly, lesbians $(\mathrm{B}=-1.32, p<0.001$, $\mathrm{OR}=0.27,95 \% \mathrm{CI}: 0.12,0.58)$, bisexuals $(\mathrm{B}=-1.48, p<0.01, \mathrm{OR}=0.23,95 \%$ CI: $0.09,0.60)$, and respondents with any other sexual orientations $(B=-1.17$, $p<0.05, \mathrm{OR}=0.31,95 \% \mathrm{CI}: 0.12,0.79$ ) had a lower chance of becoming a victim to homo-/transnegative incidents when 
Table 3 Binary logistic regression analysis of variables predicting homo-/transnegative incidents $(n=576)$

\begin{tabular}{|c|c|c|c|c|c|}
\hline Variable & B & SE B & $\begin{array}{l}\text { Wald } \\
\mathrm{X}^{2}(1)\end{array}$ & $p$ & $\operatorname{Exp}(B)$ \\
\hline \multicolumn{6}{|c|}{ Organizational frame (Ref. organized sports clubs) } \\
\hline $\begin{array}{l}\text { - For-profit organization (e.g., fitness } \\
\text { center) }\end{array}$ & 0.13 & 0.40 & 0.11 & 0.740 & 1.14 \\
\hline $\begin{array}{l}\text { - Other organization (e.g., company } \\
\text { sport) }\end{array}$ & 0.55 & 0.51 & 1.15 & 0.283 & 1.73 \\
\hline $\begin{array}{l}\text { - Informal group (non-organized/self- } \\
\text { organized) }\end{array}$ & 0.09 & 0.47 & 0.03 & 0.852 & 1.09 \\
\hline - Other & 0.27 & 0.76 & 0.12 & 0.727 & 1.31 \\
\hline \multicolumn{6}{|l|}{ Type of sport (Ref. team sports) } \\
\hline - Individual sports & -0.36 & 0.34 & 1.11 & 0.292 & 0.70 \\
\hline \multicolumn{6}{|l|}{ Performance level (Ref. recreational) } \\
\hline - Competitive & 0.46 & 0.36 & 1.59 & 0.208 & 1.58 \\
\hline - High performance & 1.11 & 0.58 & 3.60 & 0.058 & 3.03 \\
\hline \multicolumn{6}{|l|}{ Gender identity (Ref. cisgender) } \\
\hline - Non-cisgender & 2.43 & 0.40 & 36.57 & 0.000 & $11.35^{* * *}$ \\
\hline \multicolumn{6}{|l|}{ Sexual orientation (Ref. gay) } \\
\hline - Lesbian & -1.32 & 0.39 & 11.23 & 0.001 & $0.27^{* * * *}$ \\
\hline - Bisexual & -1.48 & 0.49 & 9.10 & 0.003 & $0.23^{* *}$ \\
\hline - Other & -1.17 & 0.48 & 6.02 & 0.014 & $0.31^{*}$ \\
\hline Likelihood ratio $X^{2}(11)$ & \multicolumn{5}{|c|}{$70.83^{* * *}$} \\
\hline Hosmer-Lemeshow $X^{2}{ }_{(8)}$ & \multicolumn{5}{|c|}{$5.680(p=0.683)$} \\
\hline Cox \& Snell $R^{2}$ & \multicolumn{5}{|l|}{0.116} \\
\hline Nagelkerke $R^{2}$ & \multicolumn{5}{|l|}{0.219} \\
\hline $\begin{array}{l}\text { Ref. reference } \\
{ }^{*} p<0.05,{ }^{* *} p<0.01,{ }^{* * *} p<0.001\end{array}$ & & & & & \\
\hline
\end{tabular}

compared to gay men. Controlling for all other variables, no significant effects of any sports context variables were found.

Athletes documented a variety of different negative experiences. Among those who experienced homo-/transnegative episodes, verbal insults $(80.9 \%)$ and structural discrimination (71.3\%), such as unequal opportunities, unfair treatment, and exclusion, were the most common forms of negative experiences in their main sports activity. Moreover, verbal threats and intimidation occurred in $40.4 \%$ of cases, and harassment via social media, text messages, or webpages (e-bullying) took place in $36.2 \%$ of cases. Physical types of homo-/transnegative incidents happened as lighter forms of crossing the line (e.g., shoving, pushing, and inappropriate touching) in $31.9 \%$ of cases and as severe forms of physical violence (e.g., kicking, punching, and injuring) in $15.6 \%$ of cases. Looking at different forms of negative incidents, cisgender athletes experienced verbal insults significantly more frequently (95.1 vs. $69.8 \% ; \chi^{2}(1)=9.57, p<0.01$, $V=0.319)$, whereas non-cisgender participants were more often confronted with e-bullying, although this difference was not significant (41.5 vs. $29.3 \%$ ).

\section{Reactions to a specific homo-/ transnegative incident}

In the survey, participants were asked to report their reactions to a specific homo-/ transnegative experience, offering multiple-choice answers. ${ }^{2}$ Their reactions to the specifically recalled incident showed a clear preference (-Table 4). More than half the respondents (56.2\%) decided not to react at all, and a further quarter

\footnotetext{
2 In contrast to the question of whether they had had a negative personal experience in the 12 months prior to the survey, there was no time reference for this specific question. Therefore, the number of respondents in this case was higher $(n=251)$.
}

(23.9\%) decided to leave the situation, thus, not communicating the offence or discussing the incident. Cisgender athletes did not react far more often (62.1 vs. 43.9\%) and concealed the offence, while non-cisgender individuals left the situation far more often (31.7 vs. 20.1\%). Less than one-third $(29.1 \%)$ confronted the individual(s) responsible for the homo-/ transnegative episode.

\section{Discussion}

The current study aimed to assess whether and to what extent LGBTQ+ athletes in Germany are exposed to distal and proximal stressors in sports due to their sexual orientation and/or gender identity. The results of our research suggest that homoand transnegativity (i.e., discrimination and harassment of LGBTQ+ individuals) are (still) present in sports and have negative impacts on athletes. Almost half of LGBTQ+ athletes in Germany witnessed the use of homo- and transnegative language in their sports activities within the 12 months prior to the survey, and $13 \%$ reported personal negative experiences. Apart from these two objective distal conditions and incidents, the impact of proximal stressors is also evident. The vast majority of LGBTQ+ athletes who witnessed homo-/transnegative language in their sports felt offended by it. Moreover, one-fifth of all respondents felt excluded from or refrained from participating in sports. These results are within the range of findings identified elsewhere (e.g., Denison et al., 2020; Kavoura \& Kokkonen, 2020). However, comparisons of concrete frequencies and percentages are problematic because studies use different designs and time references for the questionnaires.

While distal stressors reflect external events and conditions of homo-/ transnegativity, proximal stressors are more subjective "perceptions of self as a stigmatized and devaluated minority" (Meyer, 2003, p. 678). They incorporate expectations of rejection and concealment of one's gender identity. This relates to the striking finding that the majority of LGBTQ+ individuals who referred to a specific negative episode in their sport did not react to this incident or chose to 


\begin{tabular}{|c|c|c|c|c|c|}
\hline & $\begin{array}{l}\text { Cisgen- } \\
\text { der }\end{array}$ & $\begin{array}{l}\text { Non-cis- } \\
\text { gender }\end{array}$ & Total & $X^{2}(1)$ & $\begin{array}{l}\text { Cramer's } \\
\text { V }\end{array}$ \\
\hline I did not react & 62.1 & 43.9 & 56.2 & $7.45^{* *}$ & 0.172 \\
\hline I confronted the individual(s) & 26.6 & 34.1 & 29.1 & 1.51 & - \\
\hline I left the situation & 20.1 & 31.7 & 23.9 & $4.08^{*}$ & 0.127 \\
\hline It motivated me to perform better & 8.3 & 9.8 & 8.8 & 0.15 & - \\
\hline $\begin{array}{l}\text { I officially reported it (to the coach, officials, } \\
\text { etc.) }\end{array}$ & 5.9 & 11.0 & 7.6 & 2.02 & - \\
\hline $\begin{array}{l}\text { I changed the sporting environment (club, } \\
\text { organization, sport group, etc.) }\end{array}$ & 3.6 & 6.1 & 4.4 & 0.86 & - \\
\hline I changed my behavior & 2.4 & 4.9 & 3.2 & 1.13 & - \\
\hline Other & 5.3 & 11.0 & 7.2 & 2.65 & - \\
\hline TOTAL $(n)$ & 169 & 83 & 251 & - & - \\
\hline
\end{tabular}

leave the situation. Only $7.6 \%$ reported it to a coach or official. This finding fits into the picture of additional stress for LGBTQ+ individuals. With regard to Meyer's (2003) model of minority stress, the results suggest that LGBTQ+ athletes are at risk of a higher prevalence of health disorders due to these additional stressors (LeBlanc et al. 2015).

The study systematically analyzed meso-level factors (context of sports activities) and micro-level factors (individual LGBTQ+ status) to assess the prevalence of homo-/transnegative experiences in sports in Germany. This approach revealed that witnessing homo-/ transnegative language was significantly correlated with the context of the sports activities, whereas the extent of personal negative experiences was similarly present in all sports contexts but significantly correlated with individual LGBTQ+ status.

Considering meso-level factors (i.e., the contexts of the sports activities), the data revealed that competitive and high-performance sports, as well as team sports, were more conducive to the use of discriminating language compared to recreational and individual sports. Sport participation in organized sports clubs had no significant effect when controlling for performance level and type of sport. Nevertheless, our results are in line with other studies (e.g., Krane, 2019) regarding the (rigid) heteronormative structures in competitive sports that usually take place in the context of organized club sports.

Historical research has shown that the development of modern sports was oriented towards boys and men, emphasizing specific ideal practices of embodied hetero-masculinity and, at the same time, devaluing the participation of females (Hartmann-Tews, 1996). Practices that do not follow these norms of heteromasculinity, such as those attributed to gay men, are associated with weakness and femininity and are often a sounding board for homonegative language (Smits, Knoppers, \& Elling-Machartzki, 2020). Within these heteronormative social structures, highly competitive and male-dominated sports cultures, such as football, handball, and ice hockey, are likely to evoke and enable (hyper-) masculinity. MacDonald (2018) exemplified this mechanism in her research on young ice hockey players in Canada by revealing that homonegative discourses are expected even from players and fans.

The high proportion of respondents who felt offended and discriminated against by homo-/transnegative language emphasizes its harmful impact, irrespective of the intentions (i.e., malicious or otherwise) of those who use it, which confirms the findings of Symons, O'Sullivan, and Polman (2017). Although homo-/transnegative language was far more often witnessed in team sports than in individual sports, the type of sport had no significant effect among the other predictors within the linear regression model. Conversely, in the bivariate analysis, the proportion of those who felt offended by such language was significantly higher in individual sports. A possible explanation for this discrepancy might be the widespread and normalized homo-/transnegative talk in team sports and the relative anonymity of LGBTQ+ athletes within this group, as most of them chose not to disclose their sexual orientation or gender identity. In contrast, in contexts where homo-/ transnegativity is less common and LGBTQ+ people are more exposed as individual athletes, the offence might be taken more personally.

With regard to micro-level factors that have an impact on the experiences of LGBTQ+ athletes, the data reveal a significantly higher impact of social minority stress on non-cisgender athletes compared to cisgender ones. In other words, transgender athletes and those who did not identify as male, female, or transgender had a higher level of vulnerability. This was particularly evident with regard to experiences of homo-/ transnegative episodes, which were reported to be four times higher among non-cisgender respondents. In particular, verbal threats, structural exclusion, e-bullying, and physically crossing the line were more often experienced by noncisgender athletes. Although international data are in line with our findings, this discrepancy in the German sample is far more distinct when compared with the findings from Australia (ACT Government, 2014; Demers, 2017) and other parts of Europe (Hartmann-Tews et al., 2020; Braumüller, Menzel, \& HartmannTews, 2020).

In addition to these objective external events, non-cisgender individuals are significantly more affected by proximal stressors, which are more subjective, pertain to the internalization of societal values in general (macro level) and environment-specific experiences (meso level), and have behavioral consequences. Non-cisgender athletes were more likely to feel offended by homo-/ transnegative language and had a higher share of refraining from sports than cisgender athletes. Negative experiences among LGBTQ+ people generate the 
perception of not being welcome and feeling unsafe due to their gender identity/sexual orientation. These findings confirm data from a variety of qualitative studies based on interviews with transgender youth and adults (Devís-Devís et al., 2018; López-Canada et al., 2020). They also confirm Butler's (1990) indepth theoretical analysis of the gender order, which elaborated how non-cisgender individuals thoroughly challenge the traditional binary gender order at the macro level of societies and evoke irritation and aggressive negative reactions for not being properly gendered.

Within the group of non-cisgender respondents, those who experienced homo- and transnegativity were most often female transgender (assigned male at birth and underwent a transition to female), non-binary transgender, and non-identifying individuals. This finding aligns with Cunningham's analytical model and feminist research on discrimination in organized sports in general and competitive sports in particular (Krane, 2019). With regard to organized (competitive) sports, non-cisgender athletes do not fit into the policy of sex segregation. In a context in which the values and norms of heteronormativity are physically expressed through body-centered performance and bodily appearance, non-cisgender people in general-and female transgender, nonbinary, and non-identifying athletes in particular-challenge the heteronormative order and sex segregation in sports. At the same time, the presence of female transgender athletes in competitive and high-performance sports has raised concerns regarding fairness and undue advantage. As sex segregation in sports is based on the assumption of male bodies' superior physicality, female transgender athletes are perceived as destabilizing the level playing field in sports. In turn, institutional reactions of exclusion or forced gendering by decreasing female transgender athletes' testosterone levels are attempts to strengthen the binary system (Lucas-Carr \& Krane, 2012). Therefore, female transgender as well as non-binary and non-identifying noncisgender athletes often face more con- crete transnegativity than their male transgender counterparts.

Although cisgender athletes are far less exposed to negative incidents, the data also reveal different prevalence rates within this subgroup. Gay athletes had a higher share of personal negative experiences compared with lesbian or bisexual athletes, and, in addition, they witnessed homo-/transnegative discourses in their sports significantly more often. These findings align with research on hegemonic masculine social structures in sports, which privilege men and (expected) heteronormative masculinity (Connell \& Messerschmidt, 2005), as seen in the research of MacDonald (2018) with young ice hockey players. Consequently, our data reveal that a higher share of cisgender men compared to cisgender women felt excluded from and refrained from some sports. Although there is some research on the growing acceptance of homosexuality in sports and changing attitudes towards inclusive masculinity (Anderson, 2009), our data indicate a high level of homonegativity towards gay athletes compared to lesbian athletes, which is in line with results found by other scholars (e.g., Smits et al., 2020).

\section{Conclusion}

The empirical evidence from our research indicates the importance of tackling the exclusion and discrimination faced by LGBTQ+ people in sports in general and organized sport in particular. It thus affirms the most recent initiative of the Sport Ministers Conference (Sportministerkonferenz, 2020). The value of this research with regard to the current state of scholarship is twofold. First, this study considered multiple identities (in terms of both sexual orientation and gender identity) within the umbrella group of LGBTQ+. The acronym LGBTQ+ has its strengths as a tool to raise awareness, and it has developed as a reference point for both activists and politicians. However, the results of our research confirmed critiques of the term, as from an analytical perspective, it masks important distinctions of vulnerability. Thus, further research should be aware of the complexity of diversity and intersectional identities.

Second, our research considered different sports contexts by reflecting on the broad scope of sports contexts and cultures. Adding to the current state of research is the finding that although homo-/transnegativity is experienced across all sports contexts, the use of homo-/transnegative language is not equally spread among these different sports contexts. The results suggest that organized sports should pay attention to specific contexts with a particularly high proportion of homo-/transnegative language (e.g., competitive and team sports), as this affected the majority of respondents in negative, discriminatory, and devaluating ways. Campaigns to combat homo-/transnegativity should be expanded, and antidiscrimination education should invest in raising awareness regarding how homo-/transnegative language is not only discrimination but also a potent means to support and uphold the heteronormative gender order. As such, it is a constraint on the individual development of a healthy self (Fulcher, 2017).

With regard to inclusion of LGBTQ+ individuals and antidiscrimination policies, organized sports should understand the importance of raising awareness of these issues and of having contact persons for antidiscrimination regarding GSM people. Research on gender-based violence in sports has documented the crucial role of institutionalized practices that give voice to affected persons and bystanders for the purpose of safeguarding the integrity of individuals and organizations (Hartmann-Tews, 2021).

The authors are aware of the limited external validity of the sample, as it consisted of self-selected respondents from a hidden population with unknown sociostructural parameters. Therefore, it cannot be claimed to be representative (Meyer \& Wilson, 2009). Moreover, as surveys are derived from theoretical concepts and academic cognitive maps that reflect current knowledge, qualitative research and interviews with LGBTQ+ athletes and political actors should be used in future research to complement these findings. 


\section{Corresponding address}

Ilse Hartmann-Tews
Institute of Sociology and
Gender Studies, German
Sport University Cologne
Am Sportpark Müngersdorf 6,
50933 Cologne, Germany
i.hartmann@dshs-koeln.de

Funding. This research was funded by ERASMUS+. The European Commission's support for the production of this publication does not constitute an endorsement of the contents, which reflect the views of the authors alone, and the Commission cannot be held responsible for any use that may be made of the information contained herein.

Funding. Open Access funding enabled and organized by Projekt DEAL.

\section{Declarations}

Conflict of interest. I. Hartmann-Tews, T. Menzel and B. Braumüller declare that they have no competing interests.

For this article no studies with human participants or animals were performed by any of the authors. All studies performed were in accordance with the ethical standards indicated in each case.

Open Access. This article is licensed under a Creative Commons Attribution 4.0 International License, which permits use, sharing, adaptation, distribution and reproduction in any medium or format, as long as you give appropriate credit to the original author(s) and the source, provide a link to the Creative Commons licence, and indicate if changes were made. The images or other third party material in this article are included in the article's Creative Commons licence, unless indicated otherwise in a credit line to the material. If material is not included in the article's Creative Commons licence and your intended use is not permitted by statutory regulation or exceeds the permitted use, you will need to obtain permission directly from the copyright holder. To view a copy of this licence, visit http://creativecommons.org/licenses/by/4.0/.

\section{References}

Australian Capital Territory (ACT) Government (2014). Inclusive sport survey: the sport experiences of lesbian, gay, bisexual, transgender and intersex people in the Australian Capital Territory. https://www.sport.act.gov.au/_ data/assets/pdf_file/0005/676310/140509 Inclusive_Sport_Survey_web.pdf. Accessed 25 Aug 2021.

American Psychological Association (2021). Intersex. APA dictionary of psychology. https://dictionary. apa.org/intersex (Created2 June2021). Accessed 25 Aug 2021

Anderson, E. (2009). Inclusive masculinity: the changing nature of masculinities. London: Routledge.
Anderson, E., Magrath, R., \& Bullingham, R. (2016). Out in sport: the experience of openly gay and lesbian athletes in competitive sport. London: Routledge.

Autorengruppe Bildungsberichterstattung (2020). Bildung in Deutschland 2020: Ein indikatorengestützter Bericht mit einer Analyse zu Bildung in einer digitalisierten Welt. [Education in Germany 2020. A report based on indicators with an analysis on education in a digital world]. Bielefeld: wbv.

Braumüller, B., Menzel, T., \& Hartmann-Tews, I. (2020). Gender identities in organized sports: athletes' experiences and organizational strategies of inclusion. Frontiers in Sociology, 5, 578213. https://doi.org/10.3389/fsoc.2020.578213.

Broussard, K. A., Warner, R. H., \& Pope, A. R. (2018). Too many boxes, or not enough? Preferences for how we ask about gender in cisgender, LGB and gender-diverse samples. Sex Roles, 78(9), 606-624. https://doi.org/10.1007/s11199-017 0823-2.

Bush, A., Anderson, E., \& Carr, S. (2012). The declining existence of men's homophobia in British sport. Journal for the Study of Sports and Athletes in Education, 6(1), 107-120. https://doi.org/10. 1037/0000123-019.

Butler, J. (1990). Gender trouble: feminism and the subversion of identity. London: Routledge.

Cleland, J. (2018). Sexuality, masculinity and homophobia in association football: an empirical overview of a changing cultural context. International Review for the Sociology of Sport, 53(4), 411-423. https://doi.org/10.1177/ 1012690216663189

Connell, R., \& Messerschmidt, J. W. (2005). Hegemonic masculinity: rethinking the concept. Gender \& Society, 19(6), 829-859. https://doi.org/10. 1177/0891243205278639.

Cunningham, G.B. (2019). Understanding the experiences of LGBT athletes in sport: a multilevel model. In M.H. Anshel, T. A. Petrie \& J. A. Steinfeldt (Eds.), Sport psychology. APA handbook of sport and exercise psychology, (Vol. 1, pp. 367-383). Washington: American Psychological Association.

Csonka, B. (2019). Die deutschen Landessportbünde und -verbände unter der Lupe: Eine Analyse von Strukturen für queere Belange im organisierten Sport [The German Regional Sports Associations and Federations under the microscope: An analysis of structures that serve queer interests in organised sport] [Unpublished master's thesis]. Humboldt University Berlin.

Demers, G. (2017). Sports experiences of lesbian, gay, bisexual and transgender athletes. Laval: Laval University Press.

Denison, E., Bevan, N., \& Jeanes, R. (2020). Reviewing evidence of LGBTQ+ discrimination and exclusion in sport. Sport Management Review, 24(3), 389-409. https://doi.org/10.1016/j.smr.2020. 09.003.

Denison, E., \& Kitchen, A. (2015). Out on the fields: the first international study on homophobia in sport. https://outonthefields.com/wpcontent/uploads/2020/11/Out-on-the-FieldsFinal-Report-1.pdf. Accessed 25 Aug 2021.

Deutscher Olympischer Sportbund (2019). Satzung des DOSB - geändert von der Mitgliederversammlung am 17.12.2019 in Frankfurt a.M. [DOSB Statutes - last amended by the membership assembly 17.12.2019 in Frankfurt. https:// cdn.dosb.de/user_upload/www.dosb.de/uber uns/Satzungen_und_Ordnungen/aktuelle_
Satzung 2019 Dez._2019_pdf. Accessed 25 Aug 2021.

Devís-Devís, J., Pereira-García, S., Fuentes-Miguel, J., López-Cañada, E., \& Pérez-Samaniego, V. (2018). Opening up to trans persons in physical education-sport tertiary education: two case studies of recognition in queer pedagogy. Physical Education and Sport Pedagogy, 23(6), 623-635. https://doi.org/10.1080/17408989. 2018.1485142

Doull, M., Watson, R. J., Smith, A., Homma, Y., \& Saewyc, E. (2018). Are we leveling the playing field? Trends and disparities in sports participation among sexual minority youth in Canada. Journal of Sport and Health Science, 7(2), 218-226. https://doi.org/10.1016/j.jshs.2016.10.006.

Ellard-Gray, A., Jeffrey, N. K., Choubak, M., \& Crann, S.E. (2015). Finding the hidden participant: solutions for recruiting hidden, hard-to-reach, and vulnerable populations. International Journal of Qualitative Methods, 14(5), 1-10. https://doi.org/10.1177/1609406915621420.

Elling, A., \& Janssens, J. (2009). Sexuality as a structural principle in sport participation: negotiating sports spaces. International Review for the Sociology of Sport, 44(1), 71-86. https://doi.org/ 10.1177/1012690209102639.

European Commission (2015). Special Eurobarometer 437: discrimination in the EU in 2015. https:// tgeu.org/wp-content/uploads/2016/10/EU eurobarometer_2015_437.pdf. Accessed 25 Aug 2021.

European Union Agency for Fundamental Rights (2014). EU LGBT survey: European Union lesbian, gay, bisexual, and transgender survey: main results. http://fra.europa.eu/sites/ default/files/fra-eu-lgbt-survey-main-results tk3113640enc_1.pdf. Accessed 25 Aug 2021.

Fink, J.S. (2008). Gender and sex diversity in sport organizations: concluding comments. Sex Roles, 58(1), 146-147. https://doi.org/10.1007/ s11199-007-9364-4.

Fulcher, K. (2017). That's so homophobic? Australian young people's perspectives on homophobic language use in secondary schools. Sex Education, 17(3), 290-301. https://doi.org/10. 1080/14681811.2016.1275541.

Gleaves, J., \& Lehrbach, T. (2016). Beyond fairness: the ethics of inclusion for transgender and intersex athletes. Journal of the Philosophy of Sport, 4(2), 311-326. https://doi.org/10.1080/00948705. 2016.1157485.

Greenspan, S. B., Griffith, C., \& Watson, R.J. (2019). LGBTQ+ youth's experiences and engagement in physical activity: a comprehensive content analysis. Adolescent Research Review, 4(2), 169-185. https://doi.org/10.1007/s40894-01900110-4.

Hargie, O.D.W., Mitchell, D.H., \& Sommerville, I.J.A. (2017). "People have a knack of making you feel excluded if they catch on to your difference": transgender experiences of exclusion in sport. International Review for Sociology of Sport, 52(2), 223-239. https://doi. org/10.1177/1012690215583283.

Hartmann-Tews, I. (1996). Sport für alle!? Strukturwandel des Sports im internationalen Vergleich: Deutschland, Großbritannien und Frankreich [Sport for all!? Development of structures of organized sport in comparative perspective: Germany, Great Britain and France]. Schorndorf: HofmannVerlag.

Hartmann-Tews, l., Menzel, T., \& Braumüller, B. (2020). Homo-and transnegativity in sport in 
Europe: experiences of LGBT+ individuals in various sport settings. International Review for the Sociology of Sport. https://doi.org/10.1177/ 1012690220968108.

Hartmann-Tews, I. (2021). Gender-based violence and organisational silence in voluntary sports organisations. In S. Starystach \& K. Höly (Eds.), Silence of organizations: How organizations cover up wrongdoings (pp. 169-192). Heidelberg: heiBOOKS. https://books.ub.uni-heidelberg.de/ heibooks/catalog/book/592/c11623.

Herek, G. M. (2009). Sexual stigma and sexual prejudice in the United States: a conceptual framework. In D. A. Hope (Ed.), Contemporary perspectives on lesbian, gay, and bisexual identities (pp. 65-111). Berlin, Heidelberg, New York: Springer. https:// doi.org/10.1007/978-0-387-09556-1_4.

International Lesbian and Gay Association (ILGA) (2020). ILGA-Europe rainbow map and index 2020. https://www.ilga-europe.org/ rainboweurope/2020. Accessed 25 Aug 2021.

Jones, B.A., Arcelus, J., Bouman, W.P., \& Haycraft, E. (2017). Sport and transgender people: a systematic review of the literature relating to sport participation and competitive sport policies. Sports Medicine, 47(4), 701-716. https://doi.org/10.1007/s40279-016-0621-y.

Kavoura, A., \& Kokkonen, M. (2020). What do we know about the sporting experiences of gender and sexual minority athletes and coaches? A scoping review. International Review of Sport and Exercise Psychology. https://doi.org/10.1080/1750984X. 2020.1723123

Krane, V. (2019). Sex, gender, and sexuality in sport: queer inquiries. London: Routledge.

Krell, C., \& Oldemeier, K. (2018). Queere Freizeit Inklusions- und Exklusionserfahrungen von lesbischen, schwulen, bisexuellen, trans* und ${ }^{*}$ diversen Jugendlichen in Freizeit und Sport. https://www.dji.de/fileadmin/user_ upload/bibs2018/26869_DJI_QueereFreizeit. pdf. Accessed 25 Aug 2021.

LeBlanc, A. J., Frost, D. M., \&Wight, R. G. (2015). Minority stress and stress proliferation among samesex and other marginalized couples. Journal of Marriage and Family, 77(1), 40-59. https://doi. org/10.1111/jomf.12160.

López-Canada, E., Devís-Devís, J., Valencia-Peris, A., Pereira-García, S., Fuentes-Miguel, J., \& Pérez Samaniego, V. (2020). Physical activity and sport in trans persons before and after gender disclosure: prevalence, frequency, and type of activities. Journal of Physical Activity and Health 17(6), 650-656. https://doi.org/10.1123/jpah. 2019-0192.

Lucas-Carr, C. B., \& Krane, V. (2012). Troubling sport or troubled by sport: experiences of transgender athletes. Journal for the Study of Sports and Athletes in Education, 6(1), 21-44. https://doi. org/10.1179/ssa.2012.6.1.21.

MacDonald, C. A. (2018). Insert name of openly gay hockey player here: attitudes towards homosexuality among Canadian male major midget AAA ice hockey players. Sociology of Sport Journal, 35(4), 347-357. https://doi.org/ 10.1123/ssj.2017-0133.

Melton, E., \& Cunningham, G. (2012). When identities collide. Journal for the Study of Sports and Athletes in Education, 6(1), 45-66. https://doi. org/10.1179/ssa.2012.6.1.45.

Menzel, T., Braumüller, B., \& Hartmann-Tews, I. (2019). The relevance of sexual orientation and gender identity in sport in Europe. Findings from the OUTSPORT-Survey. Institute of Sociology and Gender Studies German Sport University Cologne

Meyer, I. H. (2003). Prejudice, social stress, and menta health in lesbian, gay, and bisexual populations: conceptual issues and research evidence. Psychological Bulletin, 129(5), 674-697. https:// doi.org/10.1037/0033-2909.129.5.674.

Meyer, I. H., \& Wilson, P. A. (2009). Sampling lesbian, gay, and bisexual populations. Journal of Counseling Psychology, 56(1), 23-31. https://doi. org/10.1037/a0014587.

Parent, M. C., \& Bradstreet, T. C. (2018). Sexual orientation, bullying for being labeled gay or bisexual, and steroid use among US adolescent boys. Journal of Health Psychology, 23(4), 608-617. https://doi.org/10.1177/1359105317692144.

Scandurra, C., Braucci, O., Bochicchio, V., Valerio, P., \& Amoedo, A. L. (2019). "Soccer is a matter of rea men?" Sexist and homophobic attitudes in three Italian soccer teams differentiated by sexual orientation and gender identity. International Journal of Sport and Exercise Psychology, 17(3), 285-301. https://doi.org/10.1080/1612197X. 2017.1339728

Schweer, M. K. W. (2018). Sexismus und Homonegativität im Sport: Anmerkungen zum Status Quo interdisziplinärer Forschung [Sexism and homonegativity in sport: Remarks on the status quo of interdisciplinary research]. In M. K. W. Schweer (Ed.), Sexismus und Homophobie im Sport: Interdisziplinäre Perspektiven auf ein vernachlässigtes Forschungsfeld [Sexism and homophobia in sport: Interdisciplinary perspectives on a neglected field of research] (pp. 3-20). Berlin, Heidelberg, New York: Springer.

Semerjian, T. (2019). Making space: transgender athletes. In V. Krane (Ed.), Sex, gender, and sexuality in sport: queer inquiries (pp. 144-162). London: Routledge.

Smith, M., Cuthbertson, S., \& Gale, N. (2012). Out for Sport report:Tackling homophobia and transphobia in sport. Equality Network. https://www. equality-network.org/wp-content/uploads/ 2013/03/Out-for-Sport-Report.pdf. Accessed 25 Aug 2021.

Smits, F., Knoppers, A., \& Elling-Machartzki, A. (2020). "Everything is said with a smile": homonegative speech acts in sport. International Review for the Sociology of Sport, 56(3), 343-360. https://doi. org/10.1177/1012690220957520.

Sportministerkonferenz (2020). "Bremer Erklärung" zu sexueller Vielfalt und geschlechtlicher Identität im Sport [Bremen Declaration on sexual diversity and gender identity in sport]. https://sportministerkonferenz.de/ fileadmin/sportministerkonferenz/Downloads/ Beschluesse 44.SMK2020 Videokonferenz.pdf In Sportministerkonferenz (2020), 44. Sportministerkonferenz am 12. November 2020: Beschlüsse [44. Sport Ministers Conference, November 12, 2020: Resolutions] (pp. 8-9). Accessed 25 Aug 2021.

Symons, C. M., O'Sullivan, G. A., \& Polman, R. C. J.(2017). The impacts of discriminatory experiences on lesbian, gay and bisexual people in sport. Annals of Leisure Research, 20(4), 467-489. https://doi. org/10.1080/11745398.2016.1251327.

Symons, C. M., Sbaraglia, M., Hillier, L., \& Mitchell, A. (2010). Come out to play: The sports experience of lesbian, gay, bisexual and transgender (LGBT) people in Victoria. Institute of Sport, Exercise and Active Living and the School of Sport and Exercise, Victoria University. https://www.vu. edu.au/sites/default/files/Come\%200ut\%20To
\%20Play\%20May\%202010.pdf. Accessed 25 Aug 2021.

Tate, C.C., Ledbetter, J. N., \& Youssef, C.P. (2013). A two-question method for assessing gender categories in the social and medical sciences. Journal of Sex Research, 50(8), 767-776. https:// doi.org/10.1080/00224499.2012.690110.

Vedder, M., \& Lammert, J. (2015). Corporate Social Responsibility im vereinsgeführten Fußball: Eine empirische Analyse und kritische Würdigung am Beispiel des Umgangs mit Diskriminierung [Corporate social responsibility in club-managed football: An empirical analysis and critical appraisal using the example of dealing with discrimination]. Forschungsjournal soziale Bewegung Plus, 28(1), 1-18. http://forschungsjournal.de/ sites/default/files/fjsbplus/fjsb-plus_2015-1 vedder_lammert.pdf.

Yoon, J. H., \& So, W. Y. (2013). Differences in lifestyles including physical activity according to sexual orientation among Korean adolescents. Iranian Journal of Public Health, 42(12), 1347-1353. 